\title{
BMJ
}

\section{Implementation of the Canadian C-Spine Rule: prospective 12 centre cluster randomised trial}

\begin{abstract}
Ian G Stiell, professor and chair, ${ }^{1}$ senior scientist, ${ }^{4}$ Catherine M Clement, research program manager, ${ }^{4}$ Jeremy Grimshaw, full professor, ${ }^{4}$ Robert J Brison, professor, ${ }^{6}$ Brian H Rowe, professor and research director, Michael J Schull, associate professor, ${ }^{7}$ Jacques S Lee, assistant professor, ${ }^{7}$ Jamie Brehaut, assistant professor, ${ }^{2}$ scientist, ${ }^{4}$ R Douglas McKnight, clinical associate professor, ${ }^{9}$ Mary A Eisenhauer, associate professor, ${ }^{8}$ Jonathan Dreyer, research director and professor, ${ }^{8}$ Eric Letovsky, associate professor, ${ }^{7}$ Tim Rutledge, associate professor, ${ }^{7}$ lain MacPhail, emergency medicine physician, ${ }^{9}$ Scott Ross, emergency medicine physician, ${ }^{5}$ Amit Shah, assistant professor, ${ }^{8}$ Jeffrey J Perry, associate professor, ${ }^{1}$ scientist, ${ }^{4}$ Brian R Holroyd, professor and department head, ${ }^{5}$ Urbain Ip, emergency medicine physician, ${ }^{9}$ Howard Lesiuk, associate professor, ${ }^{3}$ George A Wells, professor ${ }^{2,4}$
\end{abstract}

${ }^{1}$ Department of Emergency Medicine, University of Ottawa, Canada

${ }^{2}$ Department of Medicine, University of Ottawa, Canada

${ }^{3}$ Division of Neurosurgery, University of Ottawa, Canada

${ }^{4}$ Clinical Epidemiology Program, Ottawa Hospital Research Institute,

${ }^{5}$ Department of Emergency Medicine, University of Alberta, Edmonton, Canada

${ }^{6}$ Department of Emergency Medicine, Queen's University, Kingston, Canada

${ }^{7}$ Division of Emergency Medicine, University of Toronto, Canada

${ }^{8}$ Division of Emergency Medicine, University of Western Ontario,

London, Canada

${ }^{9}$ Department of Emergency Medicine, University of British Columbia, Vancouver, Canada Correspondence to: I G Stiell istiell@ohrica

Cite this as: $B M J$ J 2009;339:b4146 doi:10.1136/bmj.b4146

\section{ABSTRACT}

Objective To evaluate the effectiveness of an active strategy to implement the validated Canadian C-Spine Rule into multiple emergency departments.

Design Matched pair cluster randomised trial.

Setting University and community emergency

departments in Canada.

Participants 11824 alert and stable adults presenting with blunt trauma to the head or neck at one of 12 hospitals.

Interventions Six hospitals were randomly allocated to the intervention and six to the control. At the intervention sites, active strategies were used to implement the Canadian C-Spine Rule, including education, policy, and real time reminders on radiology requisitions. No specific intervention was introduced to alter the behaviour of doctors requesting cervical spine imaging at the control sites.

Main outcome measure Diagnostic imaging rate of the cervical spine during two 12 month before and after periods.

Results Patients were balanced between control and intervention sites. From the before to the after periods, the intervention group showed a relative reduction in cervical spine imaging of $12.8 \%$ (95\% confidence interval $9 \%$ to $16 \% ; 61.7 \%$ v 53.3\%; $\mathrm{P}=0.01)$ and the control group a relative increase of $12.5 \%$ (7\% to $18 \%$; $52.8 \%$ v $58.9 \%$; $\mathrm{P}=0.03)$. These changes were significant when both groups were compared $(\mathrm{P}<0.001)$. No fractures were missed and no adverse outcomes occurred.

Conclusions Implementation of the Canadian C-Spine Rule led to a significant decrease in imaging without injuries being missed or patient morbidity. Final imaging rates were much lower at intervention sites than at most US hospitals. Widespread implementation of this rule could lead to reduced healthcare costs and more efficient patient flow in busy emergency departments worldwide. Trial registration Clinical trials NCT00290875.

\section{INTRODUCTION}

Doctors in Canada and the United States annually treat more than 13 million patients with trauma who are at risk of injury to the cervical spine. ${ }^{1}$ Few of these patients, however, have a cervical spine fracture. Current use of diagnostic imaging is inefficient, with more than $98 \%$ of cervical spine radiographs being negative for injury. ${ }^{2}$ The use of imaging varies considerably but we believe that most patients with trauma in the United States undergo imaging of the cervical spine, despite published guidelines. ${ }^{23}$ Although such imaging is a low cost procedure, it adds to healthcare costs because of high use. Many doctors now prefer computed tomography to plain radiography and concerns have been increasing about the risks of radiation from unnecessary computed tomograms. ${ }^{45}$ Additionally, immobilisation of alert and stable patients with rigid collars and backboards, often for hours while awaiting imaging, contributes to overcrowding in emergency departments and unnecessary discomfort for the patient.

Clinical decision rules help clinicians to make diagnostic and therapeutic decisions at the bedside. The rules are derived from original research and incorporate three or more variables from the history, examination, or simple tests. ${ }^{6-8} \mathrm{We}$ previously derived the Canadian C-Spine Rule for selective ordering of cervical spine imaging by prospectively evaluating 8924 patients who presented to the emergency department with blunt trauma to the head or neck. ${ }^{9}$ We then prospectively validated the resultant Canadian C-Spine Rule (figure) in 8283 patients and found high sensitivity $(99 \%, 95 \%$ confidence interval $96 \%$ to $100 \%)$, reliability, and clinical acceptability. ${ }^{10}$ This study suggested the possibility of a cervical spine imaging rate as low as $55.9 \%$.

The true value of a clinical decision rule lies in its impact on altering patient care. Most decision rules 


\section{Canadian C-Spine Rule}

For alert (Glasgow coma score $=15$ ) and stable trauma patients where cervical spine injury is a concern

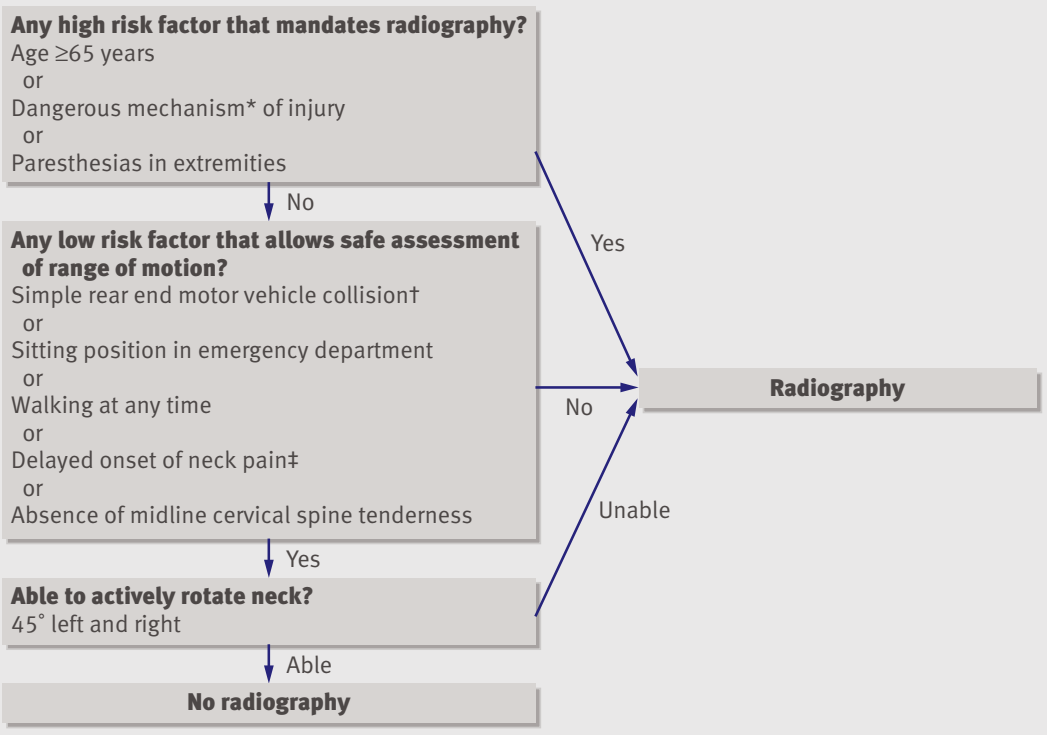

Rule not applicable if: non-trauma cases, Glasgow coma score $₫ 15$, unstable vital signs, age $<16$ years, acute paralysis, known vertebral disease, or previous surgery of cervical spine

*Fall from elevation $\geq 0.9 \mathrm{~m}$ ( 3 feet)/five stairs, axial load to head - for example, diving, motor vehicle collision high speed, (>100 km/h), rollover, ejection, motorised recreational vehicles, bicycle struck or collison

tExcludes: pushed into oncoming traffic, hit by bus or large truck, rollover, hit by high speed vehicle

$\ddagger$ Not immediate onset of neck pain

Canadian C-Spine Rule for selective ordering of cervical spine imaging

are unfortunately never used because of inadequate testing in validation or implementation studies. ${ }^{11-16}$ We evaluated the effectiveness of an active strategy to implement the Canadian C-Spine Rule in multiple emergency departments. We tested the impact of the rule on use of imaging and the effectiveness of this inexpensive and easy to implement strategy.

\section{METHODS}

We conducted a matched pair cluster randomised trial at 12 Canadian emergency departments. The methods are described elsewhere. ${ }^{17}$ These sites were stratified by teaching (six sites) or community (six sites) status and then matched according to baseline ordering rates for cervical spine imaging. Using computer generated numbers, we randomly allocated the matched sites to either intervention or control groups. Outcome measures were collected during two consecutive 12 month periods before and after the intervention. During the after period at the intervention sites, strategies were used to actively implement the Canadian CSpine Rule.

\section{Study population}

We enrolled all alert and stable adults who presented to the emergency departments after blunt trauma to the head or neck if they had neck pain; or if they had no neck pain but had a visible injury above the clavicles, had not walked, and the mechanism of the injury was considered dangerous. Additional criteria included a
Glasgow coma scale score of 15 when assessed, normal vital signs, and injury within the previous 48 hours. Patients were ineligible if they were aged under 16 , had a penetrating trauma, had acute paralysis, had known vertebral disease, or were returning for reassessment of an injury. Eligibility was determined by a different study nurse at each hospital site, according to a manual of operations.

\section{Study interventions}

Study interventions were chosen after review of the literature and consultation with experts in knowledge transfer. ${ }^{18-21}$ We used simple, inexpensive strategies to actively implement the Canadian C-Spine Rule at the six intervention sites during the after period. Physician groups in the emergency departments discussed and agreed to a policy of ordering cervical spine imaging according to the rule. Educational initiatives included distribution of previous manuscripts, pocket card and poster depictions of the rule, as well as a one hour teaching session to review the evidence and clinical application of the rule. Lastly, a mandatory real time reminder of the Canadian C-Spine Rule at the point of requisition for imaging was implemented. Any cervical spine imaging that was ordered required the doctor to check the rule criteria or to indicate the reason for overriding the rule before the diagnostic imaging department processed the request.

Although the Canadian C-Spine Rule may have been familiar to some clinicians because of journal articles and conference lectures, no specific intervention was introduced at the control sites to alter the doctors' behaviour for ordering cervical spine imaging.

\section{Outcome measures}

The primary study outcome was the proportion of eligible patients referred for diagnostic imaging of the cervical spine. Patients' daily medical census logs were reviewed to identify potential participants with injury, and eligibility was determined from emergency department nursing and doctor records and ambulance reports. We reviewed the radiology reports and census lists to determine if cervical spine imaging had been done.

Additional measures for clinical impact of implementing the Canadian C-Spine Rule included the number of clinically important cervical spine injuries (defined as any fracture, dislocation, or ligamentous instability requiring internal fixation or treatment with a halo, brace, or rigid collar $)^{22}$ not identified during the initial emergency department visit, and the number of serious adverse outcomes, such as development of a neurological deficit after the initial emergency department visit. A surveillance strategy was implemented to identify missed fractures or serious adverse outcomes. We monitored the logs of patients visits to the emergency department for 30 days to identify return visits by patients who had not undergone imaging during their initial visit. We also reviewed the logs of patients at all neurosurgical centres that are traditional referral sites for the study hospitals. 
Table 1|Characteristics of 11824 participants with injury of the cervical spine. Values are numbers (percentages) unless stated otherwise

\begin{tabular}{|c|c|c|c|c|}
\hline \multirow[b]{2}{*}{ Characteristics } & \multicolumn{2}{|c|}{ Intervention hospitals } & \multicolumn{2}{|c|}{ Control hospitals } \\
\hline & $\begin{array}{l}\text { Before period } \\
\qquad(n=3267)\end{array}$ & $\begin{array}{l}\text { After period } \\
(\mathrm{n}=3628)\end{array}$ & $\begin{array}{l}\text { Before period } \\
\quad(n=2413)\end{array}$ & $\begin{array}{l}\text { After period } \\
(n=2516)\end{array}$ \\
\hline Mean (SD) age (years) (range) & 37 (16) (16-95) & 39 (16) (16-100) & 37 (16) (16-102) & 38 (16) (16-101) \\
\hline Males & $1626(49.8)$ & $1851(51.0)$ & $1148(47.6)$ & $1229(48.8)$ \\
\hline \multicolumn{5}{|l|}{ Hospital status: } \\
\hline Teaching & $1845(56.5)$ & $2016(55.6)$ & 1179 (48.9) & $1064(42.3)$ \\
\hline Community & $1422(43.5)$ & $1612(44.4)$ & $1234(51.2)$ & $1452(57.7)$ \\
\hline \multicolumn{5}{|l|}{ Mechanism of injury: } \\
\hline Motor vehicle collision & $2510(76.8)$ & $2543(70.1)$ & $1787(74.1)$ & $1810(71.9)$ \\
\hline Fall & $318(9.7)$ & $519(14.3)$ & $292(12.1)$ & $329(13.1)$ \\
\hline Assault & $93(2.8)$ & $116(3.2)$ & $66(2.7)$ & $77(3.1)$ \\
\hline Bicycle collision & $87(2.7)$ & $117(3.2)$ & $39(1.6)$ & $56(2.2)$ \\
\hline Pedestrian struck & $77(2.4)$ & $104(2.9)$ & $39(1.6)$ & $63(2.6)$ \\
\hline Axial load (for example, diving) & $68(2.1)$ & $85(2.3)$ & $50(2.1)$ & $42(1.7)$ \\
\hline Sports & $58(1.8)$ & $76(2.1)$ & $75(3.1)$ & $72(2.9)$ \\
\hline Head struck or other & $56(1.7)$ & $68(1.9)$ & $65(2.7)$ & $67(2.7)$ \\
\hline \multicolumn{5}{|l|}{ Characteristics of motor vehicle collision: } \\
\hline Rear end & $804(24.6)$ & $786(21.7)$ & $575(23.8)$ & $585(23.3)$ \\
\hline Ejection or rollover & $154(4.7)$ & $156(4.3)$ & $129(5.3)$ & $167(6.6)$ \\
\hline Head-on & 95 (2.9) & $122(3.4)$ & $93(3.9)$ & $94(3.7)$ \\
\hline Arrived at hospital by ambulance & $1880(57.5)$ & $2155(59.4)$ & $1419(58.8)$ & $1588(63.1)$ \\
\hline Clinically important cervical spine injury*: & $32(1.0)$ & $28(0.8)$ & $18(0.7)$ & $23(0.9)$ \\
\hline Fracture & $31(0.9)$ & $28(0.8)$ & $18(0.7)$ & $23(0.9)$ \\
\hline Dislocation & $10(0.3)$ & $8(0.2)$ & $9(0.4)$ & $8(0.3)$ \\
\hline Ligamentous instability & $0(0.0)$ & $0(0.0)$ & $1(0.0)$ & $0(0.0)$ \\
\hline Clinically unimportant cervical spine injury & $8(0.2)$ & $9(0.2)$ & $22(0.9)$ & $7(0.3)$ \\
\hline Stabilising treatments: & $22(0.7)$ & $24(0.7)$ & $25(1.0)$ & $24(1.0)$ \\
\hline Internal fixation & $4(0.1)$ & $4(0.1)$ & $2(0.1)$ & $6(0.2)$ \\
\hline Halo & $5(0.2)$ & $3(0.1)$ & $5(0.2)$ & $7(0.3)$ \\
\hline Brace & $2(0.1)$ & $2(0.1)$ & $2(0.1)$ & $0(0.0)$ \\
\hline Rigid collar & $11(0.3)$ & $15(0.4)$ & $16(0.7)$ & $11(0.4)$ \\
\hline Admitted to hospital & $132(4.0)$ & $189(5.2)$ & $137(5.7)$ & $163(6.5)$ \\
\hline
\end{tabular}

*Any injury except isolated avulsion fracture of an osteophyte, isolated fracture of transverse process not involving facet joint, isolated fracture of spinous process not involving lamina, and a simple compression fracture with less than $25 \%$ loss of vertebral body height.

The secondary study outcome was performance of the Canadian C-Spine Rule during the after period at the intervention sites, where doctors checked off rule criteria on imaging requisitions. We evaluated the rule for its sensitivity, doctors' accuracy in its interpretation, and doctor compliance with its use. The doctor's interpretation was assessed by the imperfect but pragmatic approach of comparing the doctor's notation on the imaging requisition to the ideal method of interpretation made by the investigators' steering committee. Free text reasons for doctor's non-compliance were recorded.

Finally, we were unable to complete other planned evaluations as a result of cuts to our study budget by the funding agency. These included length of stay, patient satisfaction, and an economic evaluation.

\section{Statistical analysis}

We included all patients who satisfied the inclusion and exclusion criteria in the final analysis. No patient was excluded because of non-completion of a requisition or because of doctor non-compliance with the rule. Teaching and community hospitals were evaluated in subgroup analyses.

For the analysis of dichotomous data from this matched pair design we used a parametric approach based on the standard paired $t$ test $(\mathrm{k}-1=5$ degrees of freedom) to the differences in the event rates for each intervention and control site pairs. ${ }^{23-26}$ For continuous data we used the standard paired $t$ test $(\mathrm{k}-1=5$ degrees of freedom) to the differences in the mean response between the intervention and control site pairs. For the relative reductions in event rates, the stratum specific differences in means for the continuous outcome relative reduction (percentage change from baseline: (before-after) $\times 100 /$ before) were calculated and pooled across strata using a random effects metaanalysis. ${ }^{27} \mathrm{We}$ applied the weighted paired $t$ test at the cluster level using the cluster specific means and the $95 \%$ confidence intervals calculated using the weights $\left(n_{j 1} n_{j 2}\right) / n_{j}$ where $n_{j k}$ is the size of the $j^{\text {th }}$ stratum in the $\mathrm{k}^{\text {th }}$ group and $\mathrm{n}_{\mathrm{j}}$ is the size of the $\mathrm{j}^{\text {th }}$ stratum. ${ }^{24}$ 
Table 2 |Diagnostic imaging rates for 11824 participants with injury of the cervical spine during 12 month before and after periods

\begin{tabular}{|c|c|c|c|c|c|}
\hline \multirow[b]{2}{*}{ Hospitals } & \multicolumn{2}{|c|}{ No of patients } & \multicolumn{2}{|c|}{$\%$ of patients imaged } & \multirow{2}{*}{$\begin{array}{l}\% \text { relative change } \\
\qquad(95 \% \mathrm{Cl})\end{array}$} \\
\hline & Before period & After period & Before period & After period & \\
\hline \multicolumn{6}{|l|}{ Intervention hospitals* } \\
\hline \multicolumn{6}{|l|}{ Teaching hospitals: } \\
\hline Vancouver General & 738 & 919 & 73.3 & 66.2 & \\
\hline London Health Sciences & 658 & 610 & 65.5 & 57.0 & \\
\hline Ottawa Hospital & 449 & 487 & 73.9 & 68.6 & \\
\hline \multicolumn{6}{|l|}{ Community hospitals: } \\
\hline Sturgeon & 334 & 477 & 59.9 & 44.2 & \\
\hline North York General & 478 & 417 & 64.4 & 50.8 & \\
\hline Surrey Memorial & 610 & 718 & 33.1 & 33.0 & \\
\hline Total & 3267 & 3628 & $61.7(15.0) \dagger$ & $53.3(13.5) \dagger \ddagger$ & $-12.8(-9.2$ to -16.3$) \S$ \\
\hline \multicolumn{6}{|l|}{ Control hospitals* } \\
\hline \multicolumn{6}{|l|}{ Teaching hospitals: } \\
\hline University of Alberta & 597 & 516 & 58.8 & 63.6 & \\
\hline Sunnybrook Health Sciences & 254 & 243 & 61.0 & 62.1 & \\
\hline Kingston General & 328 & 305 & 43.0 & 56.1 & \\
\hline \multicolumn{6}{|l|}{ Community hospitals: } \\
\hline Royal Columbian & 349 & 533 & 47.9 & 62.1 & \\
\hline Credit Valley & 543 & 662 & 61.1 & 63.9 & \\
\hline St Thomas Elgin & 342 & 257 & 44.2 & 45.9 & \\
\hline Total & 2413 & 2516 & $52.8(8.6) \dagger$ & $58.9(7.0)+\pi$ & 12.5 (7.2 to 18.2$) \S$ \\
\hline \multicolumn{6}{|c|}{$\begin{array}{l}\text { *Listed in order of matching. } \\
\dagger \text { Mean (SD). } \\
\ddagger P=0.0119 ; \text { compares mean imaging rates in intervention hospitals during before and after periods. } \\
\S \mathrm{P}=0.0008 ; \text { compares change in mean imaging rates from before to after periods for intervention and control hospitals. } \\
\rrbracket P=0.0342 ; \text { compares mean imaging rates in control hospitals during before and after periods. }\end{array}$} \\
\hline
\end{tabular}

Reported $\mathrm{P}$ values are two tailed. The change in proportion of patients imaged from the before to after periods for each cluster was determined and used in the calculation of the differences in the event rates for each intervention and control site pair and analysed according to the plan.

To assess the performance of the rule in classifying patients for clinically important injury we calculated sensitivity along with 95\% confidence intervals. We calculated the accuracy of the doctors in interpreting the rule as simple agreement between doctors and the ideal method.

\section{Sample size}

In the calculation of sample size we took into account the complex study design: stratification by teaching versus community hospital status, matching of pairs (according to baseline imaging rates), and randomisation by cluster (the hospital as unit of randomisation and the patient as unit of analysis). From the validation study ${ }^{10}$ the average event rate for cervical spine imaging of study patients was $76 \%$ (range $63-86 \%$ ), with an annual accrual per hospital of 400 patients. That study found that imaging rates as low as 55.9\% might be possible. Through consensus of the investigators, we considered a $15 \%$ relative decrease in event rate (or an absolute decrease of $11.4 \%$ from the baseline rate of $76 \%$ ) to be a minimal clinically important change. Thus with $80 \%$ power for detecting a 0.114 difference in imaging event rates and two sided 0.05 significance level, we estimated that we would require six matched pair clusters and a total sample of 9600 patients.

\section{Follow-up period}

To evaluate the sustainability of the implementation, we followed patients for an additional 12 months at the study sites. During that period all intervention strategies were removed and the sites were unaware that data collection was ongoing. Sample size estimates were the same for this period.

\section{RESULTS}

Overall, 11824 eligible patients with injury of the cervical spine were seen at the 12 hospitals during the two study periods. Patient characteristics were similar between the before and after periods and the intervention and control groups (table 1).

The six intervention sites showed a decrease in cervical spine imaging rates from the before to after period and the six control sites showed an increase (table 2). There was an overall relative reduction in the proportion of patients referred for cervical spine imaging of $12.8 \%(95 \%$ confidence interval $9.2 \%$ to $16.3 \%)$ at the intervention sites $(61.7 \%$ v 53.3\%; $\mathrm{P}=0.01)$. The imaging rates in the before and the after period were lower than expected. Conversely, there was a relative increase of $12.5 \%(7.2 \%$ to $18.2 \%)$ at the control hospitals $(52.8 \%$ v 58.9\%; $\mathrm{P}=0.03)$. These changes from before to after were significant when the intervention and control hospitals were compared $(\mathrm{P}<0.001)$ and 
Table 3|Diagnostic imaging rates of 11824 participants with injury of the cervical spine, according to hospital type

\begin{tabular}{|c|c|c|c|c|c|c|}
\hline \multirow[b]{2}{*}{ Hospital type } & \multicolumn{2}{|c|}{ No of patients } & \multicolumn{2}{|c|}{$\%$ of patients imaged* } & \multirow[b]{2}{*}{$\%$ relative change $(95 \% \mathrm{CI})$} & \multirow{2}{*}{$\begin{array}{l}\text { P value for } \\
\text { change }\end{array}$} \\
\hline & Before period & After period & Before period & After period & & \\
\hline \multicolumn{7}{|l|}{ Intervention: } \\
\hline Community & 1422 & 1612 & $52.5(16.9)$ & $42.7(9.0)$ & $-18.0(-11.3$ to -24.2$)$ & 0.15 \\
\hline Teaching & 1845 & 2016 & $70.9(4.7)$ & $63.9(6.1)$ & $-9.5(-5.4$ to -13.4$)$ & 0.01 \\
\hline \multicolumn{7}{|l|}{ Control: } \\
\hline Community & 1234 & 1452 & $51.0(8.9)$ & $57.3(9.9)$ & $14.0(6.6$ to 22.0$)$ & 0.20 \\
\hline Teaching & 1179 & 1064 & $54.3(9.8)$ & $60.6(4.0)$ & 11.3 (3.7 to 19.5$)$ & 0.16 \\
\hline
\end{tabular}

*Values are means (SD).

$P$ values not corrected for multiple comparisons.

represent a greater than $25 \%$ relative difference between study groups (absolute difference 14.5\%).

In the subgroup analysis by hospital type the intervention was associated with a trend towards a larger relative decrease in imaging rates at community hospitals than at teaching hospitals $(18.0 \%$ v $9.5 \% ; \mathrm{P}=0.07$, table 3 ). Most of the doctors were attending doctors rather than residents, therefore the effect of doctor type was not evaluated.

At the intervention hospitals, 236 doctors were involved in implementing the decision rule during the after period. The doctors completed the rule section of the radiology requisitions in $1672(85.7 \%)$ of the 1950 eligible patients referred for imaging of the cervical spine, allowing assessment of their accuracy in interpretation of the rule (table 4). They accurately interpreted the rule for $82.9 \%$ of the patients. The most common errors in interpretation were calling dangerous mechanism when none existed and missing rear end collision and ambulation. In 40 cases radiographs were ordered despite the doctor's interpretation of the rule as negative and there were no cervical spine injuries among this group. Rarely was a reason given for failing to conform to the rule and in only two cases did the patient insist on radiography.

The decision rule could be interpreted for 1444 patients where the radiology requisition sheets were completed sufficiently. No patient discharged without imaging was subsequently found to have a clinically important cervical spine injury. The Canadian C-Spine Rule correctly identified all 23 clinically important cervical spine injuries, achieving a sensitivity of 100\% (95\% confidence interval $85 \%$ to $100 \%)$. No fractures were missed and no serious adverse outcomes occurred at any of the hospitals during the study period.

During the 12 month follow-up period, an additional 5800 eligible patients were seen, with cervical spine imaging rates dropping further at the six intervention sites, from $53.3 \%$ to $53.1 \%$, and increasing further at the six control sites, from $58.9 \%$ to $61.7 \%$. No adverse outcomes were identified at any of the study sites during this period.

\section{DISCUSSION}

An active strategy to implement the Canadian C-Spine Rule led to a significant reduction in emergency department use of diagnostic imaging for alert, stable patients with blunt trauma of the head or neck. This effect was larger in community hospitals. No patients were found to have a missed fracture or adverse outcome after discharge. Despite low baseline imaging rates, a lower rate of imaging was achieved safely, with reductions at all the intervention sites. The resultant imaging rate of $53.3 \%$ was lower than the predicted minimal rate of $55.9 \%$. Similar low rates of imaging should be achievable at many hospitals in the developed world. We believe that cervical spine imaging rates are over 90\% in US emergency departments.

This study was designed and carried out according to strict methodological standards ${ }^{2728}$ and represents the final stage of developing and testing a clinical decision rule, ${ }^{6811}$ mirroring our previous studies to derive, validate, and implement the Ottawa Ankle Rules and the Ottawa Knee Rule. ${ }^{29-35}$ A small Australian study showed a reduction in imaging when the Canadian C-Spine Rule was applied to 113 patients. ${ }^{37}$ Few clinical decision rules have this level of evaluation and we are unaware of other rules for imaging the cervical spine that have undergone explicit testing of implementation. Our 12 study nurses included a strictly defined population based cohort at each site, as defined by the operations manual. The matched pair design, in which the unit of allocation was the hospital rather than the patient, offered several advantages. By matching on baseline imaging rates we prevented an imbalance between the control and intervention groups. This design also helped to preserve the power of analysis where relatively few clusters were studied.

Previous Canadian studies showed large reductions in ankle and knee imaging after implementation of our ankle and knee rules. ${ }^{323336}$ Although the reductions noted in this trial were not as large, our previous implementation trials used expensive strategies, many of which were not practical for routine use. The implementation strategies used in this study were simple, inexpensive, and could easily be adopted on a permanent basis. It is well documented that implementation of guidelines can be difficult. A systematic review of 235 studies with rigorous evaluations of guideline dissemination and implementation strategies found that most interventions observed modest improvements in care with median absolute improvements in performance ranging from $6.0 \%$ to $13.1 \%{ }^{38}$ 
Table 4 Errors by doctors in interpreting Canadian C-Spine Rule for 1672 alert and stable patients with trauma during 12 month after period at intervention hospitals*

\begin{tabular}{lccc} 
& \multicolumn{2}{c}{ No of criteria } & \\
\cline { 2 - 4 } Criteria & Missed & Overcalled & \% errors \\
High risk: & & 3 & 11.5 \\
\hline Age $\geq 65$ years & 1 & 148 & 0.2 \\
\hline Dangerous mechanism of injury & 21 & 6 & 10.1 \\
\hline Paraesthesias in extremities & 14 & 1 & 1.2 \\
\hline Low risk: & & 0 & 8.4 \\
\hline Simple rear end motor vehicle collision & 32 & 0 & 2.0 \\
\hline Sitting position in emergency department & 10 & 0 & 0.6 \\
\hline Walking at any time & 63 & 11 & 3.8 \\
\hline Delayed onset neck pain & 13 & - & 0.8 \\
\hline Absence of midline tenderness & 10 & - & 1.3 \\
\hline Range of motion & & 1 & 3.5 \\
\hline
\end{tabular}

*Decision rule could be interpreted for 1672 patients for whom data collection sheet was completed.

Some study limitations warrant comment. The baseline cervical spine imaging rates at the intervention and control sites $(61.7 \%$ and $52.8 \%)$ were much lower than the $76 \%$ seen in the validation study and not as balanced as planned. The relative decrease in imaging rates, although shown at all intervention sites in our trial, was modest and less than the $15 \%$ difference that we had targeted. We speculate that because seven of the sites had participated in the previous validation study (three intervention and four control hospitals), the behaviour of the doctors may have already changed to follow the rule. Nevertheless, the final imaging rate at the intervention sites $(53.3 \%)$ was low, less than the $55.9 \%$ potential rate predicted, and was actually a $30 \%$ relative reduction compared with the expected baseline rate of $76 \%$. At the same time imaging rates went up at all six control sites, possibly reflecting a secular trend in usage of diagnostic imaging in increasingly crowded emergency departments. Doctors at these sites were not aware that they were in this study and were given no instructions on cervical spine imaging. The impact was greater at community hospitals, possibly because five of these sites had not participated in the validation study or perhaps because the severity of injury is generally less at such sites. Our 12 month follow-up data confirm the ongoing divergent trends in imaging use, with rates continuing to decrease at the intervention sites and continuing to increase at the control sites. This supports our belief that there is a general trend towards increased use of imaging.

While the impact may seem modest, we showed a greater than 25\% difference in imaging effect between the intervention and control sites. The overall imaging rate achieved in the after period at the intervention sites was very low and would be a worthy accomplishment for any hospital. The subgroup of three community hospitals in the intervention group had not previously participated in the developmental studies and had the most impressive results, with an extremely low final imaging rate of $42.7 \%$ and a relative reduction of
$18 \%$. Another issue is that the absolute number of patients increased in the after period in both intervention and control sites. However, the absolute number of imaging procedures declined at the intervention sites and increased at the control sites and we are confident that there was no change in the characteristics of patient populations from the before to the after periods and no selection bias. Finally, while we are confident that we missed no adverse outcomes, it is conceivable but unlikely that a few patients subsequently underwent diagnostic imaging at a non-study hospital.

Although our strategy was simple and inexpensive to implement, doctor compliance with the requisition was more difficult than expected. This strategy required the radiology technicians to act as gatekeepers, a role with which they were not always comfortable. In the implementation studies for the Ottawa Ankle Rules and Ottawa Knee Rule, doctor compliance was 95\% and 93\%, respectively. ${ }^{336}$ Additionally, there was some misinterpretation of the rule by doctors, which may reflect the greater complexity of this rule or perhaps a desire to order imaging despite the rule.

This trial supports the previous findings that the Canadian C-Spine Rule is highly sensitive for identifying clinically important injuries of the cervical spine ${ }^{910}$ and also shows that it can be widely implemented in emergency departments by doctors. Most importantly, this implementation can be achieved safely with minimal risk to patients because the rule was designed to be sensitive for injuries and only modestly specific. For 380 patients with injury the cumulative sensitivity of the rule in the combined derivation, validation, and implementation studies was 99.7\% (95\% confidence interval $98 \%$ to $100 \%$ ), with no harm to any patient. The issues of doctors' compliance and misinterpretation should be addressed by training that emphasises correct interpretation of high and low risk criteria. Although the study was carried out in Canada, we see no reason why the results would not be applicable to emergency departments throughout most of the developed world. We recognise that some US jurisdictions, due to a private hospital system and doctors' fear of litigation, may be more challenged to implement the Canadian C-Spine Rule. Widespread adoption of the rule could lead to optimisation of diagnostic imaging rates, less exposure to radiation, and improved patient flow in busy emergency departments. This would prevent prolonged and uncomfortable immobilisation on high acuity area beds for patients with relatively minor injuries.

In conclusion, an active strategy to implement the Canadian C-Spine Rule led to a significant decrease in the use of cervical spine imaging without missed injuries or patient morbidity. Final imaging rates were low compared with most hospitals in the United States. Widespread implementation of the Canadian C-Spine Rule could safely lead to reduced healthcare costs and more efficient patient flow in busy emergency departments. 


\section{WHAT IS ALREADY KNOWN ON THIS TOPIC}

Use of diagnostic imaging to exclude cervical spine injury is inefficient in emergency

departments

Prolonged unnecessary immobilisation of the cervical spine adds to overcrowding in emergency departments and patient discomfort

Previous studies have shown the potential of the Canadian C-Spine Rule to reduce safely the use of cervical spine imaging and immobilisation

\section{WHAT THIS STUDY ADDS}

Imaging rates for cervical spine injuries were significantly reduced in hospitals that implemented the Canadian C-Spine Rule compared with control hospitals

Intervention hospitals had very low imaging rates after implementation

No fractures were missed and no adverse events occurred

We thank the physicians, nurses, and radiology technicians at the intervention hospitals for their cooperation with the study; the following research staff at the study hospitals: Vancouver General, Vancouver, British Columbia (Jan Buchanan); London Health Sciences Centre, London, Ontario (Evelyn Gilkinson); Ottawa Hospital-Civic Campus, Ottawa, Ontario (Kim Bradbury); Sturgeon, St Albert, Alberta (Michelle Pachal); North York General, Toronto, Ontario (Jodie Hale, Andrea Ennis); Surrey Memorial, Surrey, British Columbia (Linda Gormley); University of Alberta, Edmonton, Alberta (Harris Lari, Terry Shewchuk); Sunnybrook and Women's College Health Sciences Centre, Toronto, Ontario (Sharon Ramagnano, Deborah Wright); Kingston General, Kingston, Ontario (Kathy Bowes); Royal Columbian, New Westminster, British Columbia (Percy MacKerricher); Credit Valley, Mississauga, Ontario (Jeannie Brewster, Jennifer Yantha); St Thomas Elgin, St Thomas, Ontario (Lorraine Rollins); our colleagues at the Ottawa Hospital Research Institute (Christine Leclair, Sheryl Domingo, My-Linh Tran, and Irene Harris) for their assistance with this project; and Carol Bennett for invaluable assistance in preparing the manuscript

Funding: This study received support for peer review from the Canadian Institutes of Health Research. The funding agency had no role in the design, conduct, or reporting of the study.

Competing interests: None declared.

Ethical approval: This study was approved by the hospital research ethics boards, without the need for informed consent as all patients were treated with the same imaging protocol. Individual patients were not randomised and the degree of risk was judged to be minimal. A proposed data safety monitoring board was not convened because no adverse events occurred during the study.

1 McCaig LF, Nawar EW. National hospital ambulatory medical care survey: 2004 Emergency department summary. Adv Data 2006;372.

2 Stiell IG, Wells GA, Vandemheen K, Laupacis A, Brison R, Eisenhauer MA, et al. Variation in emergency department use of cervical spine radiography for alert, stable trauma patients. Can Med Assoc J 1997; 156:1537-44

3 Hoffman JR, Mower W, Wolfson AB, Todd K, Zucker M. Validity of a set of clinical criteria to rule out injury to the cervical spine in patients with blunt trauma. N Engl J Med 2000;343:94-9.

4 Martin DR, Semelka RC. Health effects of ionising radiation from diagnostic CT. Lancet 2006;367:1712-4.

5 Brenner DJ, Hall EJ. Computed tomography—an increasing source of radiation exposure. N Engl J Med 2007;357:2277-84.

6 Laupacis A, Sekar N, Stiell IG. Clinical prediction rules: a review and suggested modifications of methodological standards. JAMA 1997;277:488-94.

7 McGinn TG, Guyatt GH, Wyer PC, Naylor CD, Stiell IG, Richardson WS Users' guides to the medical literature: XXII: how to use articles about clinical decision rules. JAMA 2000;284:79-84.

8 Stiell IG, Wells GA. Methodologic standards for the development of clinical decision rules in emergency medicine. Ann Emerg Med 1999;33:437-47.

9 Stiell IG, Wells GA, Vandemheen K, Clement C, Lesiuk H, De Maio VI, et al. The Canadian cervical spine radiography rule for alert and stable trauma patients. JAMA 2001;286:1841-8.

10 Stiell IG, Clement C, McKnight RD, Brison R, Schull MJ, Rowe BH, et al. The Canadian C-Spine Rule versus the NEXUS low-risk criteria in patients with trauma. N Engl J Med 2003;349:2510-8.
11 Lee TH. Evaluating decision aids: the next painful step. J Gen Intern Med 1990;5:528-9.

12 Grimshaw IM, Russell IT. Effect of clinical guidelines on medical practice: a systematic review of rigorous evaluations. Lancet 1993;342:1317-22.

13 Cabana MD, Rand CS, Powe NR, Wu AW, Wilson MH, Abboud P-AC et al. Why don't physicians follow clinical practice guidelines? JAMA 1999;282:1458-65

14 Abboud P-AC, Cabana MD. Understanding barriers to the adoption of clinical decision rules (correspondence). Ann Emerg Med 2001;38:703-4.

15 Reilly BM, Evans AT. Translating clinical research into clinical practice: impact of using prediction rules to make decisions. Ann Intern Med 2006;144:201-9.

16 Brehaut JC, Stiell IG, Graham ID. Will a new clinical decision rule be widely used? The case of the Canadian C-Spine Rule. Acad Emerg Med 2006;13:413-20.

17 Stiell IG, Grimshaw J, Wells GA, Coyle D, Lesiuk H, Rowe BH, et al. A matched-pair cluster design study protocol to evaluate implementation of the Canadian C-Spine Rule in hospital emergency departments: phase III. Implement Sci 2007;2.

18 Grimshaw JM, Shirran L, Thomas RE, Mowatt G, Fraser C, Bero L, et al. Changing provider behaviour: an overview of systematic reviews of interventions. Med Care 2001;39:|12-45.

19 Oxman AD, Thomson MA, Davis DA, Haynes RB. No magic bullets: a systematic review of 102 trials of interventions to improve professional practice. Can Med Assoc J 1995;153:1423-31.

20 Bero LA, Grilli R, Grimshaw JM, Harvey E, Oxman AD, Thomson MA. Closing the gap between research and practice: an overview of systematic reviews of interventions to promote the implementation of research findings. BM/ 1998;317:465-8.

21 Davis DA, Thomson MA, Oxman AD, Haynes RB. A systematic review of the effect of continuing medical education strategies. JAMA 1995;274:700-5.

22 Stiell IG, Vandemheen K, Brison R, Cass DE, Dreyer J, Eisenhauer MA, et al. Validity evaluation of the cervical spine injury proxy outcome assessment tool in the CCC Study. Acad Emerg Med 1999;6:434.

23 Korn R. The paired t-test. Appl Stat 1984;33:230-1.

24 Donner A, Donald A. Analysis of data arising from a stratified design with cluster as unit of randomization. Stat Med 1987;6:43-52.

25 Gail MH, Mark SD, Carroll RJ, Green SB, Pee D. On design considerations and randomization-based inference for community intervention trials. Stat Med 1996;15:1069-92.

26 Donner A, Klar N. Design and analysis of cluster randomization trials in health research. London: Arnold, 2000.

27 Thompson SG, Pyke SD, Hardy RJ. The design and analysis of paired cluster randomized trials: an application of meta-analysis techniques. Stat Med 1997:16:2063-79.

28 Campbell MK, Elbourne DR, Altman DG. CONSORT statement: extension to cluster randomised trials. BMJ 2004;328:702-8.

29 Hahn S, Puffer S, Torgerson D, Watson J. Methodological bias in cluster randomised trials. BMC Med Res Methodol 2005;5.

30 Stiell IG, Greenberg GH, McKnight RD, Nair RC, McDowell I, Worthington JR. A study to develop clinical decision rules for the use of radiography in acute ankle injuries. Ann Emerg Med 1992;21:384-90.

31 Stiell IG, Greenberg GH, McKnight RD, Nair RC, McDowell I, Reardon $\mathrm{M}$, et al. Decision rules for the use of radiography in acute ankle injuries: refinement and prospective validation. JAMA 1993;269:1127-32.

32 Stiell IG, McKnight RD, Greenberg GH, McDowell I, Nair RC, Wells GA, et al. Implementation of the Ottawa ankle rules. JAMA 1994:271:827-32.

33 Stiell IG, Wells G, Laupacis A, Brison R, Verbeek R, Vandemheen K, et al. A multicentre trial to introduce clinical decision rules for the use of radiography in acute ankle injuries. BMJ 1995;311:594-7.

34 Stiell IG, Greenberg GH, Wells GA, McKnight RD, Cwinn AA, Cacciotti T, et al. Derivation of a decision rule for the use of radiography in acute knee injuries. Ann Emerg Med 1995;26:405-13.

35 Stiell IG, Greenberg GH, Wells GA, McDowell I, Cwinn AA, Smith NA, et al. Prospective validation of a decision rule for the use of radiography in acute knee injuries. JAMA 1996;275:611-5.

36 Stiell IG, Wells GA, Hoag RA, Sivilotti MLA, Cacciotti TF, Verbeek RP, et al. Implementation of the Ottawa knee rule for the use of radiography in acute knee injuries. JAMA 1997;278:2075-8.

37 Kerr D, Bradshaw L, Kelly AM. Implementation of the Canadian CSpine Rule reduces cervical spine $x$-ray rate for alert patients with potential neck injury. J Emerg Med 2005;28:127-31.

38 Grimshaw JM, Thomas RE, Maclennan G, Fraser C, Ramsay CR, Vale L, et al. Effectiveness and efficiency of guideline dissemination and implementation strategies. Health Technol Assess 2002.

Accepted: 7 August 2009 